10.1515/rjes -2016-0007

\title{
IN SEARCH OF THE INVISIBLE ROOTS: IMMIGRANT EXPERIENCES IN JHUMPA LAHIRI'S UNACCUSTOMED EARTH
}

\author{
DANIELA ROGOBETE \\ University of Craiova, Romania
}

\begin{abstract}
This paper attempts an analysis of the metaphorical strategies Jhumpa Lahiri uses in her 2008 collection of short stories Unaccustomed Earth in order to explore and comment on the intricate relations and the complex web of feelings and resentments, longing and attachment that make up the essence of family life as shaped by the diasporic experience. In this volume, Lahiri particularly focuses on the conflicting emotions engendered by migration, on the articulation of displacement and reintegration, and on the capacity to fully assume the diasporic experience and turn it into a meaningful assertion of one's identity.
\end{abstract}

Keywords: belonging, emplacement, Indian diaspora, intertextuality, translation

\section{Introduction}

Acknowledged as one of the most appreciated Indian-American writers of the day, Jhumpa Lahiri reveals her artistic skill through close analyses of the intricate web of human relationships and the fragile mechanisms of the human mind and soul when faced with the traumatic experience of exilic displacement. Her main concern generally goes with the subtly nuanced conflicts between the first, second and third-generation Indian immigrants and with their endeavour to acknowledge, if not to completely come to terms with, their roots and past.

The article focuses on Lahiri's use of metaphoric and intertextual strategies that go beyond the biographical coordinates of exile towards the universal dimensions of human displacement, in a successful attempt to merge personal and collective experience, individual and universal aspects and her particular means used to convey the general estrangement and acute sense of loss that seem to afflict her characters. Caught between identities and cultures, between nostalgia and alienation, these people constantly try to translate themselves into a new cultural idiom and to counterbalance their vulnerability and the inherent fragility of their relationships with the reliance upon the concreteness of the material world they inhabit and the apparently comfortable security of the American life style. Lahiri makes the palpable materiality of her characters' environments dissolve into elusiveness and gradually transfers its solidity and corporeality to the world of emotions.

Jhumpa Lahiri's exquisite treatment of objects in her Pulitzer winning collection of short stories Interpreter of Maladies (1999) is prolonged and further nuanced in Unaccustomed Earth (2008). In her second collection of short stories she uses the same strategy of projecting a world of feelings, personal traumas and life changing conflicts upon small details and apparently insignificant objects that acquire prophetic, symbolic and metaphorical functions. She goes deeper this time projecting the material world - seen as an intermediary between people, between their lost dreams and their new expectations, between 
their invisible roots and their newly developed sprouts - upon a more generous context that encompasses real and metaphorical spaces and transforms the characters' individual experiences into a universal drama of displacement and alienation.

\section{When Hyphenation Is a State of Being}

Indian diaspora has most often been envisaged in the light of the trauma it engenders, the sense of loss, uprootedness and the ambiguous status it always confers to the persons placed "between locations of residence and locations of belonging" (Gilroy 2000:124). The difficulty of fully containing the diasporic experience within definite theoretical paradigms comes from the tendency to level and generalise totally different historic contexts and socioeconomic circumstances that have engendered different diasporic communities. Indian diaspora has a long history. Starting with the "ancient diaspora" of the Buddhist travellers to Central and Eastern Asia, the ghummakar tradition of the migrant Gypsies, the subsequent migration of traders and indentured workers, old and new, colonial and postcolonial, the Indian diaspora has most frequently been regarded as a unitary phenomenon though it generally fails to encompass all the aspects that fully characterise the dynamics of displacement. Theorists generally relate the cultural dynamics of diasporic movements to social adjustment, resilience and cultural persistence, integration, ethnicity and to more specific dimensions such as gender, caste and regional and religious identity.

The ever intensifying processes of globalisation and hypermobility and the increased awareness of distinct diasporic communities actively engaged in a permanent negotiation and renegotiation of identity have gradually changed the perception on immigration which has been redefined in terms of class, gender and motivation. Most theorists rely upon a common ethnic consciousness and an active associative life, upon the permanent contact with a homeland and tight relations with various groups of the same ethnic origin, when trying to define diaspora (see Raghuram et al. 2008). The common point of all definitions of diaspora is the central idea of a home and homeland in relation to which any diasporic entity tries to define itself.

Present day diasporic displacement is regarded as "brain circulation", whereas diaspora itself as "brain bank" (Sahay 2009:7). The new redefinitions of diaspora, now engaged in an economic exchange process that has long ceased to be unidirectional, modified the general perception on Indians and demolished old cultural stereotypes, redefining the traditional understanding of the old dichotomies centre/margins, home/away and the strict relationship formerly established between geographical location and identity. Hybridity, interculturation and syncretism, key elements of our age, are engendered by the cultural hyphenation of diaspora whose dynamic is still characterised by a double allegiance to the currently occupied space and to a lost home.

If social, economic and political reassessments of the Indian diaspora strive to get as objective as possible, most of its literary analyses are often criticised for their generalising formula, their exoticism and biased redefinitions of national and ethnic identities. The legitimacy of many Westernised representations of a country one has deliberately left behind is often questioned, as well as the authenticity of the cultural construct of a unitary India offered by some texts and the essential Indianness they try to promote.

Jhumpa Lahiri herself was sometimes criticised and accused of simplifying the diasporic experience, of over-generalising and depoliticising it, of embracing the perspective of the well-off second-generation Indian American immigrant, devoid of financial worries and ignoring issues such as gender, caste and class or religious identity. The remarkable success of her fiction and the huge appeal to the reading public were considered to be a proof of the 
mercantile character of her writings. "I've never written for anyone other than myself" (Grossman 2008) was her reply to the accusation of lending her voice to all ethnic immigrants, irrespective of their regional, religious identity and social status, and projecting her own experience upon the entire diasporic phenomenon.

Member of a second-generation Bengali immigrant family, New York-based, Londonborn, raised in Rhode Island, Lahiri got quickly aware of "the intense pressure to be two things, loyal to the old world and fluent in the new", exerted on the Indian-American writer (Chand qtd. in Dhingra 2012:12). She belongs to the generation called "Midnight's grandchildren" in honour of Rushdie's famous novel and in recognition of his part in the revival of the Indian novel written in English.

Unaccustomed Earth (Lahiri 2008), winner of the Frank O'Connor Prize, continues to discuss the issues put forth in her previous works, problems of belonging and unbelonging, identity and multiple identification, roots and uprootedness, displacement and multiple locations. All these issues revolve around the idea of home and the necessity and importance of translating the hyphen inherent to the diasporic condition.

Diasporas are people who would want to explore the meaning of the hyphen, but perhaps not press the hyphen for fear that this would lead to massive communal schizophrenia. They are precariously lodged within an episteme of real or imagined displacements, self-imposed sense of exile; they are haunted by specters, by ghosts arising from within that encourage irredentist or separatist movements. (Mishra 2007:2)

Vijay Mishra's definition of diaspora based on the "meaning of the hyphen" matches Lahiri's interest in translating one hyphenated side into the other, in negotiating the boundaries between the two, and in finding meaningful strategies to give voice to what Mishra referred to as the "specters" and "ghosts" that arise from within. In Lahiri's case the hyphen seems to bridge the space between "exilic emplacement" and "diasporic selffashioning", as theorised by Nico Israel (2000) in his study on diaspora Outlandish: Writing between exile and diaspora. The "haunting ghosts" Mishra was talking about arise here from all the gaps and silences created after a failed attempt to perfectly translate and retranslate homes, cultural and linguistic identities, as well as personal dreams and collective expectations, interpreted in her novels as aching absences, family secrets and screaming silences.

"Exilic emplacement", generally explained as a means of being placed in and inscribed within a particular space (see Israel 2000), characterises Jhumpa Lahiri's depiction of her first-generation Bengali immigrants inclined to long for a lost home and recreate imaginary homelands, in a continuous oscillation between displacement and multiple emplacements. Diasporic "self-fashioning" seems to better characterise Lahiri's secondgeneration immigrants, focused upon defining their identity in relation to a real, coherent and unitary space. They are still haunted by the memory of the Other space but are mainly preoccupied with taming the Otherness of the former generations and projecting their sense of loss and nostalgic appropriation of reality upon an objectively mapped out space. Besides this "tension without resolution" of the "modernist metaphor of exilic deracination (seen as the subject's melancholic refusal or inability to repudiate his or her geographic and cultural 'roots') and the postmodern/postcolonial metaphor of diaspora (as potential hybridity or multiple rooting of national and ethnic identities)" (Israel 2000:18) - Lahiri introduces yet another element, a sort of "situatedness-in-displacement", to use Bruce Robbins' term (1992:173), which gives space a surreal, highly flexible dimension. By bringing into discussion the diasporic dimensions of the third-generation Indian/Bengali immigrants, Lahiri 
tackles the issue of possible diasporic mutations into a post-diaspora community with a totally different understanding of origins and a new conception of the chronotope of belonging.

In Unaccustomed Earth Lahiri juxtaposes all these exilic/diasporic dimensions at the same time playing with tropes and participating in a new rhetoric and tropology of displacement, focused on irretrievable loss as a key image. She usually builds her firstgeneration immigrants as people hovering in the space of in-betweenness, caught in endless processes of metaphorical trans-lations between a point of departure and a space of arrival; the second-generation immigrants are mostly characterised by means of metonymic and synecdochic strategies that focus upon fragmentation and hybridisation whereas the few characters belonging to the third-generation immigrants receive again a metaphoric treatment, a strategy mainly relying upon dissemination and return to the origins.

Lahiri envisages translation as the essence of the migrant/diasporic condition and as a key metaphor of our times since the migrant is permanently forced to translate his/her Otherness into new idioms. Related to the important emphasis placed upon translation in all her writings, she confessed in an interview that "almost all my characters are translators in so far as they must make sense of the foreign to survive" (Lahiri qtd. in Dhingra 2012:37). "While I write as an American or as an Indian, about things American or Indian or otherwise, one thing remains the constant: I translate therefore I am" seems to be Lahiri's favourite motto (Dhingra 2012:37).

Fully embraced in The Interpreter of Maladies (Lahiri 1999), the idea of translation as defining the diasporic condition goes beyond the linguistic realm well into the psychological effects of displacement, trauma and loss interpreted through a highly suggestive strategy of materialising emotions and metaphorising objects. Her treatment of translation reveals it as one of the most significant cognitive processes of understanding Otherness and is similar to Rushdie's identification operated on etymological grounds between translation/trans-lation and metaphor (with the same meaning of "carrying across" and thus similar in their capacity to bear significance across cultures, languages and identities); it also bears similarities to Steiner's inherent "internalised inscription" of linguistic and cultural Otherness as "every act of communication between human beings increasingly takes the shape of an act of translation" (Steiner 1971:19).

\section{Deep Roots Rest in Infinity}

Lahiri uses "ideas rather than places" and metaphors rather than plain definitions in order to translate the traumatic experience of her characters in Unaccustomed Earth (2008), always in search of a way of expressing the space of "untranslatability" inherent in any diasporic experience. Loss, absence and silence thus become the main coordinates of the diasporic space Lahiri creates in her fiction.

In her first novel The Namesake (2003) Jhumpa Lahiri introduces the idea that identity goes deeper than spatial location, physical dislocation and socio-political circumstances. She also initiates the permanent game of metaphorically translating Self into Other, here into there, belonging into unbelonging and multiple belongings. "We all came out of Gogol's overcoat" (Lahiri 2008:78) one character in The Namesake says, quoting Dostoyevsky and alluding to a cultural allegiance and inherited otherness that both transcend physical spatiality. This cultural allegiance is present in Unaccustomed Earth which begins with a motto from Nathaniel Hawthorne's Custom House and establishes the central preoccupation of all the short stories collected in the volume with the complex process of diasporic readjustment of first and second-generation Indian immigrants and the mutations it causes on family relationships. "Striking roots" in a foreign land and translating the idea of "home" become the 
precondition of the evolution of humanity. 'We all come out of Hawthorne's Scarlet Letter' might be the reply of the characters in Unaccustomed Earth as America's cultural heteronomy could find a point of reference in Hawthorne, he himself a descendent of the first Puritan settlers.

Human nature will not flourish, any more than a potato, if it be planted and replanted, for too long a series of generations, in the same worn-out soil. My children have had other birthplaces and, so far as their fortunes may be within my control, shall strike their roots into unaccustomed earth. (Hawthorne qtd. in Lahiri 2003)

This motto also provides Lahiri with one of the most suggestive structural metaphors of the volume, which is the agricultural metaphor that leads her to "two senses of genealogy": the interethnic and the intertextual. "Indeed the genetic aspect of ethnicity is simply intertextuality in the biological context: both in-group reproduction as well as ethnic outmarriage yield different cultural and genetic 'texts' in the bodies and cultural identities of new subjects" (Dhingra 2012:11).

The double-meaning genealogy is alluded to in the short story that opens the volume with gardening as its central metaphor. Once again, Lahiri pays close attention to minute details and objects charged with an overwhelming power of suggestion. For Ruma, the postcards she receives from her father become strange epitomes of minimalist family relations and a means of mapping out her father's wanderings around the world, revealing at the same time her difficulty in adjusting to new places (a second-generation immigrant, born in America but displaced from Brooklyn to Seattle). For the father, they are a token of simplicity, a form of appropriating his adoptive world, a celebration of simple things as they always end up with "'Be happy, love Baba' as if the attainment of happiness was as simple as that" (Lahiri 2008:4). During her father's visit, small gestures bring father and daughter closer and the growing of the small garden he plants in her backyard connotes the tightening of their relationship, a tentative connection to her father, to her past and her forgotten roots.

As everywhere in Lahiri's writings there is a deep sense of loss, a deterministic feeling that everything, even "the entire enterprise of having a family, of putting children on this earth... was flawed from the start" (Lahiri 2008:55). But beyond this inherent loss, Lahiri almost always insinuates a grain of hope, placing loss and gain, determinism and acceptance in a strange dialectical relationship. Hope, in this case, is connoted by the discovery Akash, Ruma's little son, makes of his own roots. His grandfather's gift for him - a Pinocchio puppet - projects upon Akash all the symbolism embedded in the transformation of a wooden puppet into a real boy. Akash's gradual bond with his grandfather and with his Indian past is achieved through his participation in the tendering of the garden, his lessons of Bengali and his discovery that buried seeds yield future harvests. In a highly symbolic gesture he imitates his grandfather and starts sowing toys and personal belongings into the ground.

The desperate attempt to "strike roots" in a foreign soil is variously illustrated in this volume. In "Hell-Heaven", Aparna's inability to adjust to her adoptive land (having moved out of India to Berlin and out of Berlin to the Central Square in America) and her obsessive cling to the past make her desperately want to recreate her homeland at all costs, and pushes her into the trap of a love triangle. Pranab, the student she befriends and receives into her home like a brother, makes Aparna and her husband feel estranged as if coming from two different worlds. Pranab recreates Aparna's lost world through music, films, poetry and cooking. Loss comes in this short story under the guise of mother-daughter alienation and failure of both Indian traditional and mixed marriages.

All stories embrace the perspective of the American born Indian child who judges his/her parents according to American standards, mostly for their failure to adjust and for their 
transforming existence into a "life sentence of being foreign" (Lahiri 2008:138) as in "Only Goodness". The first generation immigrants' fascination with the Promised Land and its wonderful images of a bright future for their children, make them ignorant of the suffering of these children born between worlds and condemned to always strike roots across two different continents and come to terms with both.

\section{Aching Absences and Speaking Silences}

In her attempt to translate the multiple aspects of the diasporic experience Jhumpa Lahiri encounters and bridges various spaces of untranslatability represented by silences, gaps and absences. The solution she finds to cover these spaces is to project her characters' silent traumas and unexpressed longings upon their material surrounding that takes over all this emotional investment and acts as a substitute, an omen and gap-filler.

Besides the prevalent agricultural metaphor, there is an entire range of images that make up metaphors of connection and disconnection or images ambiguously placed in between. The postcards in Unaccustomed Earth (Lahiri 2008) or the image of the "house" in "Hema and Kaushik" could be such examples. A burn in a skirt in "A Choice of Accommodations" occasions a close analysis of a mixed marriage. While attending a wedding, imperceptible frictions and signs of marital dysfunction become visible, significantly represented under the guise of a circular burn in the wife's skirt the two spouses try to conceal by sticking close together. The burn becomes at the same time a mark of their estrangement and a small impediment that only makes them aware of their failures but brings them closer. From the sagged balloon connoting dashed expectations and personal failure in "Only Goodness" to the lost bangle in "Hema and Kaushik" Lahiri's metaphorically charged objects speak of the inevitable dissipation of a family and the unavoidable "cracks" that tear families apart.

One of the most notable aching absences in the volume is that of a well-defined home/homeland. The house acquires metonymic dimensions in most of these short stories as it evokes a gone by world and becomes a material substitute for somebody absent in the family. In the last novella of the collection, "Hema and Kaushik", the "house" acquires complex nuances, from identification with particular persons to embodying different aspects of the experience of exile. Immigration itself is seen as a sequence of home building in the attempt to find a lost home or settle into another one, and this implies moving around a set of items that epitomises the idea of home. Different ways of approaching and envisaging houses become emblematic for different approaches of the diasporic condition. The first generation endeavours to set up households, to strike roots and thus make up for the absence of the home they left. In contrast, the second generation, as illustrated by Hema and Kaushik, tries hard not to build homes and get stuck to one place for fear of being displaced and obliged to live once again their parents' trauma.

Kaushik internalises the condition of the perpetual outsider, a position reinforced by his profession as a photographer, the eternal witness of other people's traumas. Through photography he finds the best way to colonise reality, to appropriate and master the new world in a different way than his parents, developing a symbolic and elusive attachment to materiality and its frozen representations in photographs. Photography becomes in this volume one of Lahiri's favourite strategies of playing with absences and presences with signifiers and signifieds, referents and implied significances. It is, too, a form of "home building" by taking possession and taming the material world, making it more familiar and inhabitable. 
One of the most suggestive metaphoric images, characteristic for Lahiri's perspective on the Indian family in exile is the ekphrastic introduction of van Eyck's painting, The Arnolfini Marriage, in "Only Goodness". The small mirror in this painting becomes the focal point of the composition, capturing and reflecting back to the viewer the ceiling, the floor and the outside world that includes van Eyck himself. The mirror functions as a silent witness revealing, as all Lahiri's short stories, small but significant details, small secrets and concealed objects that might make the difference between a loving family and one doomed to fail. Like van Eyck, Lahiri lets herself be seen at times, sharing with us her diasporic experience. Van Eyck's portrait as well as the photographs alluded to in the volume play with the elusiveness of presences and absences, with the unreliability, fragility and persistence of memories and the interesting effects drawn by the implicit though mostly invisible presence of the photographer/painter/writer and the conviction that there is always something that remains unsaid and unseen, that escapes and cannot be translated.

\section{Conclusion}

Jhumpa Lahiri's Unaccustomed Earth (2008) continues to explore the Indian diaspora in America, in terms of deracination, readjustment to a new place, redefinition of identity and impact on family relationships. First and second generation immigrants find themselves separated by different expectations and life values and obliged to translate themselves in the idioms of the two cultures they simultaneously inhabit. The stories in this collection focus on the metaphor of "striking roots into unaccustomed earth", which allows Lahiri to dwell on the problem of exilic emplacement and the conflict between unbelonging and multiple belonging. Her perspective on diaspora is that of "being in translation", of appropriating and internalising a new reality in both linguistic and cultural dimensions. Losses, silences and absences, recurrent in Lahiri's fiction, are subtly negotiated with and metaphorically translated so that in the end, the diasporic condition could be defined as a balanced mixture of 'lost-and-found', 'loss and gain', a middle path where the translated migrant becomes a "self-reflexive translation that holds up for scrutiny the translator, his or her presuppositions, standards and life philosophy" (Cronin 2003:141).

\section{References:}

Cronin, Michael. 2003. Translation and Globalisation. New York: Routledge.

Dhingra, Lavina. 2012. Naming Jhumpa Lahiri: Canons and Controversies. Plymouth: Lexington.

Gilroy, Paul. 2000. Against Race: Imagining Political Culture Beyond the Colour Line. Cambridge MA: Belknap Press of Harvard University Press.

Grossman, Lev. 2008. "Jhumpa Lahiri: The Quiet Laureate". Time. 8 May. Available at: www.time.com/time/magazine/article/0,9171,1738511,00.html [Accessed 2015, March 12].

Israel, Nico. 2000. Outlandish: Writing between exile and diaspora. Stanford: Stanford University Press.

Lahiri, Jhumpa. 2008. Unaccustomed Earth. New York: Vintage Books.

Lahiri, Jhumpa. 2003. The Namesake. Boston: Houghton Mifflin.

Lahiri, Jhumpa. 1999. Interpreter of Maladies. Boston: Houghton Mifflin.

Mishra, Vijay. 2007. The Literature of the Indian Diaspora: Theorising the Diasporic Imagination. London: Routledge.

Raghuram, Parvati, Ajaya Kumar Sahoo, Brij Maharajah, Dave Sangha (Eds.). 2008. Tracing an Indian Diaspora: Contexts, Memories, Representation. Sage Publications.

Robbins, Bruce. 1992. “Comparative Cosmopolitanism”. Social Text 31-32 (1992):169-186.

Sahay, Anjali. 2009. Indian Diaspora in the United States: Brain Drain or Gain? Plymouth: Lexington.

Steiner, George. 1971. Extraterritorial: Papers on Literature and the Language Revolution. New York: Atheneum. 


\section{Note on the author}

Daniela ROGOBETE is Senior Lecturer at the Department of British, American and German Studies, University of Craiova, Romania. She holds a PhD in Postcolonial Studies, and this continues to be her major field of study. Her publications include When Texts Come into Play-Intertexts and Intertextuality (2003), Metaphor-Between Language and Thought (2008), and Deconstructing Silence-Ambiguity and Censored Metaphors in Salman Rushdie's Fiction (2010), in addition to various co-edited collections of essays, articles published in national and international journals, and literary translations into Romanian. Her research interests also include intertextuality, aesthetics and visual culture. 